\title{
THERMAL BRIDGES AT WOOD FRAME CONSTRUCTION
}

\author{
Ligia Moga ${ }^{\text {a, } *, \text { I. Moga }}{ }^{\text {a }}$ \\ ${ }^{a}$ Technical University of Cluj-Napoca, Faculty of Civil Engineering, Buildings and Management Department, 25 Baritiu Str., \\ Romania
}

Received: 21.09.2015 / Accepted: 28.10.2015 / Revised: 23.11.2015 / Available online: 15.12.2015

DOI: $10.1515 /$ jaes-2015-0023

KEY WORDS: Wood Structures, Heat Transfer, Thermal Performance, Energy Performance

\begin{abstract}
:
The paper presents the results of numerical analysis on the effects of thermal bridges at wood frame buildings with or without thermal insulation placed on the exterior surface of the wall. The heat flow crossing the wooden thermal bridges, respectively the linear heat transfer coefficients $\psi$ and the temperature factors $f_{\mathrm{Rsi}}$, can be established based on the plane temperature field in stationary thermal regime. The "PSIPLAN" computer program used to determine the temperature field, derived from the original program "CIMPLAN" with its first version developed in 1980. The program allows graphic description of the plane section of a thermal bridge and discretizes automatically the section on both axes in accordance with the stipulations of the EN ISO 102111:1995 standard and EN ISO 10211:2007 standard. The computer program generates automatically the system of equations that is solved using iterative methods until the heat flows on the two surfaces of the section are balanced. The calculation results are presented with numerical values and in a graphical manner by isothermal surfaces. The program has various libraries that include several types of wood thermal bridges.
\end{abstract}

\section{INTRODUCTION}

Thermal bridges of building envelope components are areas where the heat flow increases in comparison with the current field area of the component. They arise due to a change of material or a change in the building geometry, because of the penetration of the building envelope components by materials with different conductivity or due to the contact between two types of elements. This often leads to higher heat losses and to formation of risk points that can lead to surface condensation appearance and mold growth. To limit as much as possible these phenomena, appropriate constructive measures should be applied starting from the initial design stage (Moga, 2009).

Heat losses caused by existing thermal bridges in the building envelope are calculated using specific heat

\footnotetext{
* Corresponding author: ligia.moga@ccm.utcluj.ro
}

transfer coefficients. The loss of heat caused by linear thermal bridges is expressed by the linear heat transfer coefficient denoted by $\psi$. The $\psi$ value is defined as the additional heat loss due to thermal disturbance, on a minimum length of one meter when a temperature difference of $1 \mathrm{~K}$ exists between indoor and outdoor air. Unit of measurement for the linear thermal transfer coefficient is $\mathrm{W} /(\mathrm{m} \bullet \mathrm{K})$. The numerical value of $\psi$ obtained through calculations is influenced by several characteristics: quality of construction detail, the method of choosing the sizes, the junction between two elements and the value of the thermal transmittance in the adjacent field of the elements (the current field of the element), the fairness in choosing thermal conductivities and contour conditions. If the chosen value for the interior superficial thermal resistance is chosen $\mathrm{R}_{\mathrm{si}}=0.25\left(\mathrm{~m}^{2} \mathrm{~K}\right) / \mathrm{W}$, than the $\mathrm{f}_{\mathrm{Rsi}}$ factor is used at establishing the minimum temperature on the surface of 
the element in order to avoid the phenomena of mold growth (Ascione, 2013; Cappelletti, 2011; Asdrubali 2012).

\section{CALCULATION OF THE LINEAR HEAT TRANSFER COEFFICIENT $\Psi$ AND TEMPERATURE FACTOR $_{\text {RSI }}$}

\subsection{Generalities}

The linear heat transfer coefficient and the temperature factor are established using specific programs for thermal bridges calculation. The linear heat transfer coefficient is given by:

$$
\psi=L_{2 D}-\sum_{j=1}^{N} U_{j} \cdot l_{j}
$$

where:

$\Psi$ is the linear thermal transmittance of the linear thermal bridge separating the two environments being considered;

$\mathrm{L}^{2 \mathrm{D}}$ is the thermal coupling coefficient obtained from a $2 \mathrm{D}$ calculation of the component separating the two environments being considered;

$\mathrm{Uj}$ is the thermal transmittance of the 1D ,j" component separating the two environments being considered

$\mathrm{lj}$ is the length within the 2D geometrical model over which the value $U_{j}$ applies;

$\mathrm{N}$ is the number of $1 \mathrm{D}$ components

The $\mathrm{f}_{\mathrm{Rsi}}$ value is obtain applying the following::

$$
f_{R_{s i}}(x, y)=\frac{\theta_{s i}(x, y)-\theta_{e}}{\left(\theta_{i}-\theta_{e}\right)}
$$

where:

$f_{R s i}(x, y)$ is the temperature factor for the interior surface in the point defined by coordinates $(\mathrm{x}, \mathrm{y})$;

$\theta_{\mathrm{si}}(\mathrm{x}, \mathrm{y})$ is the temperature on the interior surface of the element, in the point defined by coordinates $(\mathrm{x}, \mathrm{y})$;

$\theta_{\mathrm{i}}$ is the temperature of the interior air;

$\theta_{\mathrm{e}}$ is the temperature of the exterior air.

The calculation of the interior surface temperature in point defined by coordinates $(\mathrm{x}, \mathrm{y})$ can be calculated with the following equation:

$$
\theta_{\mathrm{si}}(\mathrm{x}, \mathrm{y})=\mathrm{f}_{\mathrm{Rsi}}(\mathrm{x}, \mathrm{y}) \cdot\left(\theta_{\mathrm{i}}-\theta_{\mathrm{e}}\right)+\theta_{\mathrm{e}}
$$

The temperature differences ratio or the temperature factor must be calculated with an error smaller than 0.005 .

The thermal transmittance $U^{\prime}\left(\mathrm{W} / \mathrm{m}^{2} \mathrm{~K}\right)$ and the thermal resistance $R^{\prime}$ will be calculated using the equations given below. The point thermal transmittance $\chi$ is neglected due to its negligible value obtained in calculations.

$$
U^{\prime}=\frac{1}{R^{\prime}}=\frac{1}{R}+\frac{\sum\left(\psi \cdot l_{j}\right)}{A}
$$

where:

$\mathrm{R}$ is the thermal resistance from the current field of the element $\left(\mathrm{m}^{2} \mathrm{~K} / \mathrm{W}\right)$ :

$$
\mathrm{R}^{\prime}=\mathrm{r} \cdot \mathrm{R}
$$

from where it results that: $r=\frac{R^{\prime}}{R}[-]$

where:

$r$ is the reduction coefficient for the unidirectional thermal resistance.

\subsection{The algorithm of the program}

To determine the two-dimensional thermal coupling coefficients $\mathrm{L}^{2 \mathrm{D}}$ used to calculate the thermal transmittance, the $\psi$ coefficient and the $\mathrm{f}_{\mathrm{Rsi}}$ factor it is necessary to solve the plan temperature field in stationary thermal regime given by the equation:

$\frac{\partial}{\partial x}\left[\lambda(x, y) \cdot \frac{\partial \theta(x, y)}{\partial x}\right]+\frac{\partial}{\partial y}\left[\lambda(x, y) \cdot \frac{\partial \theta(x, y)}{\partial y}\right]=0$

where:

$\theta$ is the temperature in the node defined by coordinates $(\mathrm{x}, \mathrm{y})$;

$\lambda(\mathrm{x}, \mathrm{y})$ has constant value for the materials defining the section.

For numerical solving of the differential equation with partial derivatives of second order (see 6), the geometrical model between the vertical cutting plans was divided using sectioning axes, parallel to the axes of the plane cartesian system. The discretisation steps $\Delta \mathrm{x}$ and $\Delta \mathrm{y}$ generated the orthogonal calculations network (mesh) of the plane temperature field. The meshing steps were defined by distances between 1 and $10 \mathrm{~mm}$ in all directions. The temperature field calculation was performed considering that the lateral cutting planes are adiabatic surfaces.

Due to a high volume of calculations required for solving the plane heat transmission equation in stationary thermal regime, imposed the development of a calculation program called „PSIPLAN” (PSIP). This program uses the high precision numerical method of heat balance in the nodes of the computing network (mesh) in accordance with EN ISO 10211:2007, Annex A, section A.2 (EN ISO 10211, 1995, 2007). 
Energy balance equations of the obtained system, written automatically by the program, include a large number of nodes, more than 10,000 nodes, and is solved by iterative calculation method. The conditions for convergence of the obtained results are the following:

- energy balance of the heat flows in each ,j" node of the calculation mesh located inside the element or on its surface, must be $\Sigma \Phi_{\mathrm{j}}=0$;

- energy balance of the heat flows from the interior surface with the ones from the exterior surface of the element must be equal $\Phi_{\mathrm{si}}=\Phi_{\mathrm{se}}$.

The number of discretisation steps of the network and number of contour conditions, is unlimited. Geometrical model of thermal bridges, complies with the modeling rules foreseen in Section 4 of EN ISO 10211-2:2001 (EN ISO 10211, 2001) regarding linear thermal bridges. Discretisation of the plane geometrical model is performed automatically by the calculation program, thus result the $2 \mathrm{D}$ discretisation network. Error estimator generates the need of extending the degree of network computing subdivision. This is done automatically by the program until both conditions are satisfied:

- between the flows on the inner and outer surface of the whole section exists a difference of $0.0001 \mathrm{~W}$,

- in each node of the 2D computing network exists a difference of $0.000001 \mathrm{~W}$, condition superior than the one from EN ISO 10211:2007, Annex A, point A.2 (EN ISO 10211, 2007).

The „PSIPLAN” program uses the calculation method for determining the linear heat transfer coefficient according to point 10.3 and the temperature factor according to section 11.2 of (EN ISO 10211-2: 2001).

\section{CASE STUDY}

\subsection{Thermal bridges description}

From the multitude of analyzed solutions are presented the results for a timber wall, in uninsulated and thermally insulated variant. The first analyzed solution (figure 1) is the case of an uninsulated wall having mineral wool as internal thermal insulation. Four case scenarios were considered for the thickness of the mineral wool layer $d_{v}(10 \mathrm{~cm}, 12 \mathrm{~cm}, 14 \mathrm{~cm}, 16$ $\mathrm{cm})$ and three case scenarios for the stud $\mathrm{d}_{\mathrm{m}}(38 \mathrm{~mm}$, $50 \mathrm{~mm}, 80 \mathrm{~mm}$ ).

An OSB interior sheathing of $10 \mathrm{~mm}$ on which a 12.5 $\mathrm{mm}$ gypsum board is placed on the interior surface. OSB sheathing is also placed on the exterior surface of the wall. The thermally insulated variant is similar from the dimensional point of view to the uninsulated variant mentioned before.

The thickness of the exterior thermal insulation was considered for two case scenarios, respectively $5 \mathrm{~cm}$ and $10 \mathrm{~cm}$.

- Calculation hypothesis: geometry and thermal conductivity of materials (CSTB catalogue).

Plate of plaster cardboard d $=12,5 \mathrm{~mm}, \lambda=0,25 \mathrm{~W} /(\mathrm{m} \cdot \mathrm{K})$

Wood-based panel (OSB or CTBH) $\mathrm{d}=10 \mathrm{~mm}, \lambda=0,13$ $\mathrm{W} /(\mathrm{m} \cdot \mathrm{K})$

Pine wood (spruce) $\lambda=0,18 \mathrm{~W} /(\mathrm{m} \cdot \mathrm{K})$

Mineral wool insulation $\lambda=0,04 \mathrm{~W} /(\mathrm{m} \cdot \mathrm{K})$

Wood-based panel (OSB or CTBH) $\mathrm{d}=12 \mathrm{~mm}, \lambda=0,13$

$\mathrm{W} /(\mathrm{m} \cdot \mathrm{K})$

Expanded polystyrene insulation $\lambda=0,040 \mathrm{~W} /(\mathrm{m} \cdot \mathrm{K})$

Decorative render $\mathrm{d}=8 \mathrm{~mm}, \lambda=0,70 \mathrm{~W} /(\mathrm{m} \cdot \mathrm{K})$

- Boundary conditions $(\mathrm{C} 107,2005)$ :

Interior: $\mathrm{T}_{\mathrm{i}}=+20^{\circ} \mathrm{C}$

$\mathrm{R}_{\mathrm{si}}=0,13\left(\mathrm{~m}^{2} \cdot \mathrm{K}\right) / \mathrm{W}$ for $\psi$ calculation

$\mathrm{R}_{\mathrm{si}}=0,25\left(\mathrm{~m}^{2} \cdot \mathrm{K}\right) / \mathrm{W}$ for $\mathrm{f}_{\mathrm{Rsi}}$ calculation

Exterior: $\mathrm{T}_{\mathrm{e}}=0^{\circ} \mathrm{C}$

$\mathrm{R}_{\mathrm{se}}=0,04\left(\mathrm{~m}^{2} \cdot \mathrm{K}\right) / \mathrm{W}$ vertical or horizontal value

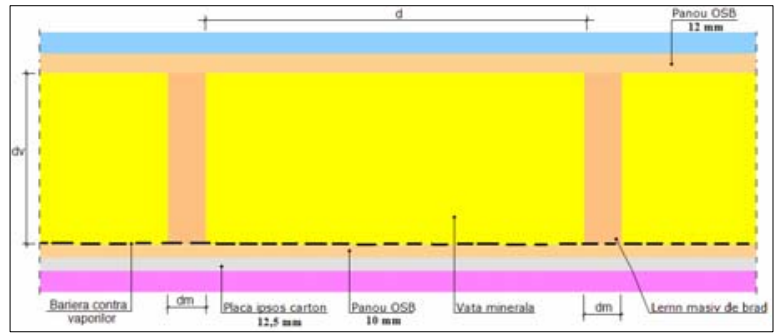

Figure 1. Horizontal section exterior wall - uninsulated

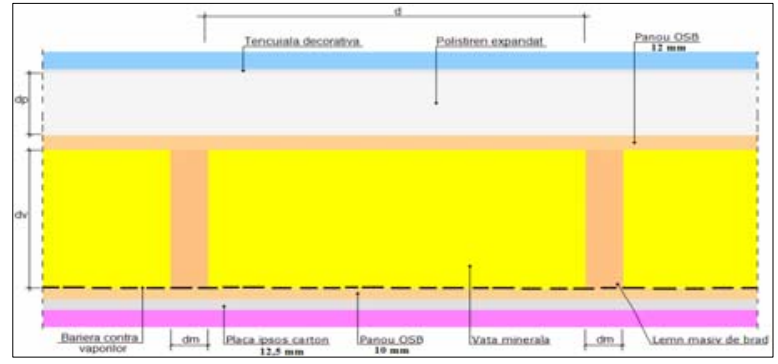

Figure 2. Horizontal section exterior wall - thermally insulated

\subsection{Thermal performance evaluation of a panel}

The thermal performance of a wood panel of $3000 \mathrm{x}$ $2700 \mathrm{~mm}$ was studied, for the uninsulated and thermal 
insulated case. The constructive detail is the one presented at 3.1.

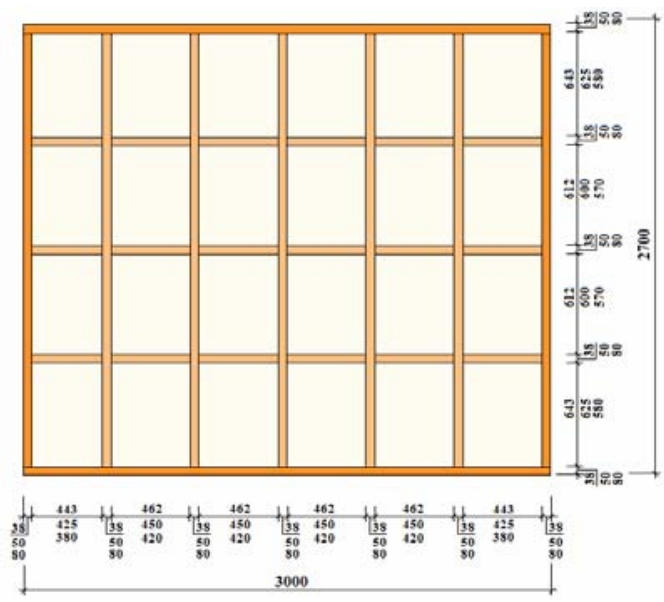

Figure 3. Wall panel $-3000 \times 2700 \mathrm{~m}$

\section{THERMAL BRIDGES RESULTS}

\subsection{Numerical results}

The $\psi$ and $\mathrm{f}_{\mathrm{Rsi}}$ values were determined for a central stud and a marginal stud of a wall panel.

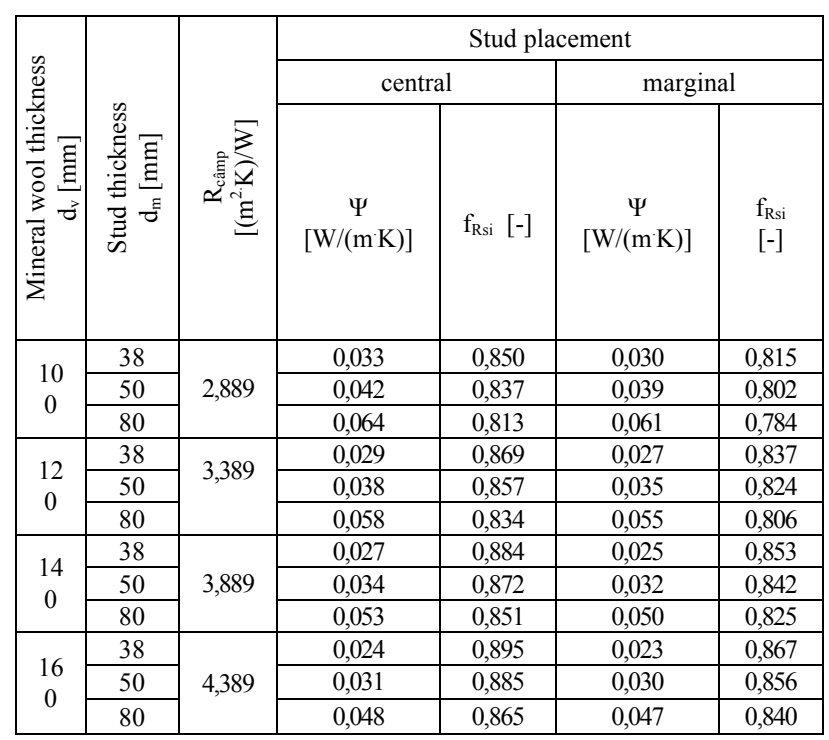

Table 1. Uninsulated exterior wall

\begin{tabular}{|c|c|c|c|c|c|c|}
\hline \multirow{3}{*}{ 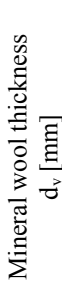 } & \multirow[b]{3}{*}{ 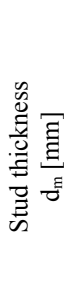 } & \multirow[b]{3}{*}{ 音 } & \multicolumn{4}{|c|}{ Stud placement } \\
\hline & & & \multicolumn{2}{|c|}{ central } & \multicolumn{2}{|c|}{ marginal } \\
\hline & & & $\begin{array}{c}\Psi \\
{[\mathrm{W} /(\mathrm{m} \cdot \mathrm{K})]}\end{array}$ & $\mathrm{f}_{\mathrm{Rsi}}[-]$ & $\begin{array}{c}\Psi \\
{[\mathrm{W} /(\mathrm{m} \cdot \mathrm{K})]}\end{array}$ & $\begin{array}{l}\mathrm{f}_{\mathrm{Rsi}} \\
{[-]}\end{array}$ \\
\hline \multirow{3}{*}{$\begin{array}{c}10 \\
0\end{array}$} & 38 & \multirow{3}{*}{4,151} & 0,013 & 0,906 & 0,011 & 0,892 \\
\hline & 50 & & 0,017 & 0,900 & 0,014 & 0,889 \\
\hline & 80 & & 0,029 & 0,891 & 0,021 & 0,885 \\
\hline \multirow{3}{*}{$\begin{array}{c}12 \\
0\end{array}$} & 38 & \multirow{3}{*}{4,651} & 0,013 & 0,913 & 0,012 & 0,899 \\
\hline & 50 & & 0,017 & 0,907 & 0,014 & 0,895 \\
\hline & 80 & & 0,024 & 0,898 & 0,021 & 0,891 \\
\hline \multirow{3}{*}{$\begin{array}{c}14 \\
0\end{array}$} & 38 & \multirow{3}{*}{5,151} & 0,013 & 0,919 & 0,012 & 0,905 \\
\hline & 50 & & 0,016 & 0,913 & 0,014 & 0,900 \\
\hline & 80 & & 0,024 & 0,904 & 0,021 & 0,896 \\
\hline \multirow{3}{*}{$\begin{array}{c}16 \\
0\end{array}$} & 38 & \multirow{3}{*}{5,651} & 0,013 & 0,924 & 0,011 & 0,910 \\
\hline & 50 & & 0,016 & 0,919 & 0,014 & 0,906 \\
\hline & 80 & & 0,024 & 0,909 & 0,021 & 0,901 \\
\hline
\end{tabular}

Table 2. Thermally insulated $(5 \mathrm{~cm})$ exterior wall

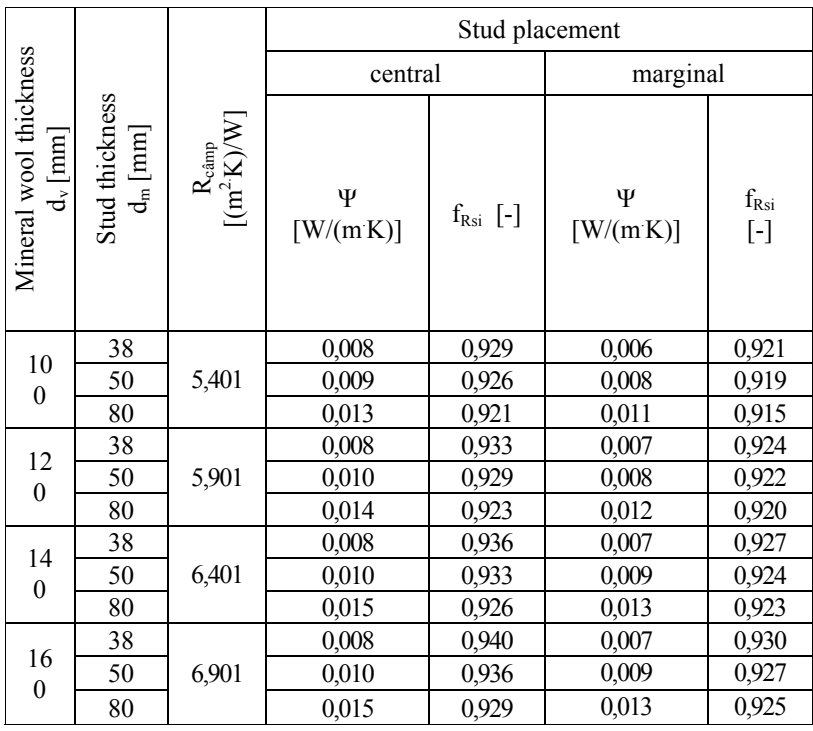

Table 3. Thermally insulated $(10 \mathrm{~cm})$ exterior wall 


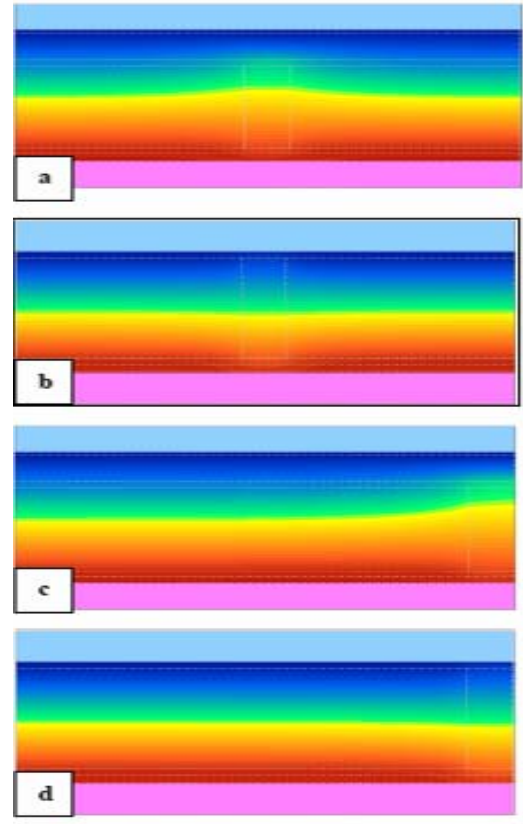

Figure 4. Isothermal surfaces for central stud (a) uninsulated wall, (b) thermally insulated wall, and for marginal stud (c) uninsulated wall, (d) thermally insulated wall

\section{WALL PANEL RESULTS}

In order to establish the thermal performance of a timber wall panel (figure 4) the detail included all types of thermal bridges mentioned before. The calculations were made for all case scenarios.

\subsection{Numerical results}

\begin{tabular}{|c|c|c|c|c|c|}
\hline \multirow{3}{*}{ 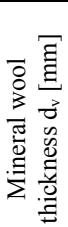 } & \multirow{3}{*}{ 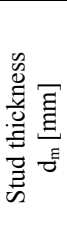 } & \multicolumn{4}{|c|}{ Wall panel } \\
\hline & & \multicolumn{4}{|c|}{ Uninsulated } \\
\hline & & $\begin{array}{c}\Psi \cdot 1 \\
{[\mathrm{~W} / \mathrm{K}]}\end{array}$ & $\begin{array}{c}\mathrm{U}^{\prime} \\
{\left[\mathrm{W} /\left(\mathrm{m}^{2} \mathrm{~K}\right)\right]}\end{array}$ & $\begin{array}{c}\mathrm{R}^{\prime} \\
{\left[\left(\mathrm{m}^{2} \mathrm{~K}\right) \mathrm{W}\right]}\end{array}$ & $\begin{array}{c}r \\
{[-]}\end{array}$ \\
\hline \multirow{3}{*}{100} & 38 & 1,036 & 0,474 & 2,110 & 0,73 \\
\hline & 50 & 1,308 & 0,508 & 1,970 & 0,68 \\
\hline & 80 & 1,942 & 0,586 & 1,707 & 0,59 \\
\hline \multirow{3}{*}{120} & 38 & 0,933 & 0,410 & 2,438 & 0,72 \\
\hline & 50 & 1,182 & 0,441 & 2,268 & 0,67 \\
\hline & 80 & 1,762 & 0,513 & 1,951 & 0,58 \\
\hline \multirow{3}{*}{140} & 38 & 0,846 & 0,362 & 2,766 & 0,71 \\
\hline & 50 & 1,074 & 0,390 & 2,566 & 0,66 \\
\hline & 80 & 1,609 & 0,456 & 2,194 & 0,56 \\
\hline \multirow{3}{*}{160} & 38 & 0,775 & 0,323 & 3,091 & 0,70 \\
\hline & 50 & 0,984 & 0,349 & 2,863 & 0,65 \\
\hline & 80 & 1,480 & 0,411 & 2,436 & 0,55 \\
\hline
\end{tabular}

\begin{tabular}{|c|c|c|c|c|c|}
\hline \multirow{3}{*}{ 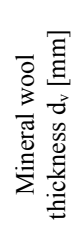 } & \multirow{3}{*}{ 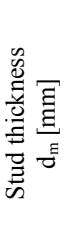 } & \multicolumn{4}{|c|}{ Wall panel } \\
\hline & & \multicolumn{4}{|c|}{ Thermally insulated - $5 \mathrm{~cm}$ EPS } \\
\hline & & $\begin{array}{c}\Psi \cdot 1 \\
{[\mathrm{~W} / \mathrm{K}]}\end{array}$ & $\begin{array}{c}\mathrm{U}^{\prime} \\
{\left[\mathrm{W} /\left(\mathrm{m}^{2} \mathrm{~K}\right)\right]}\end{array}$ & $\begin{array}{c}\mathrm{R}^{\prime} \\
{\left[\left(\mathrm{m}^{2} \mathrm{~K}\right) \mathrm{W}\right]}\end{array}$ & $\begin{array}{c}\mathrm{r} \\
{[-]}\end{array}$ \\
\hline \multirow{3}{*}{100} & 38 & 0,414 & 0,292 & 3,424 & 0,83 \\
\hline & 50 & 0,507 & 0,303 & 3,295 & 0,79 \\
\hline & 80 & 0,707 & 0,328 & 3,047 & 0,73 \\
\hline \multirow{3}{*}{120} & 38 & 0,416 & 0,266 & 3,754 & 0,81 \\
\hline & 50 & 0,509 & 0,278 & 3,599 & 0,77 \\
\hline & 80 & 0,717 & 0,304 & 3,294 & 0,71 \\
\hline \multirow{3}{*}{140} & 38 & 0,411 & 0,245 & 4,084 & 0,79 \\
\hline & 50 & 0,505 & 0,256 & 3,899 & 0,76 \\
\hline & 80 & 0,715 & 0,282 & 3,540 & 0,69 \\
\hline \multirow{3}{*}{160} & 38 & 0,402 & 0,227 & 4,413 & 0,78 \\
\hline & 50 & 0,496 & 0,238 & 4,197 & 0,74 \\
\hline & 80 & 0,706 & 0,264 & 3,786 & 0,67 \\
\hline
\end{tabular}

\begin{tabular}{|c|c|c|c|c|c|}
\hline \multirow{3}{*}{ 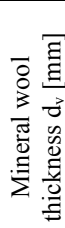 } & \multirow{3}{*}{ 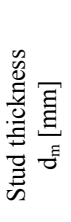 } & \multicolumn{4}{|c|}{ Wall panel } \\
\hline & & \multicolumn{4}{|c|}{ Thermally insulated $-10 \mathrm{~cm}$ EPS } \\
\hline & & $\begin{array}{c}\Psi \cdot 1 \\
{[\mathrm{~W} / \mathrm{K}]}\end{array}$ & $\begin{array}{c}\mathrm{U}^{\prime} \\
{\left[\mathrm{W} /\left(\mathrm{m}^{2} \mathrm{~K}\right)\right]}\end{array}$ & $\begin{array}{c}\mathrm{R}^{\prime} \\
{\left[\left(\mathrm{m}^{2} \mathrm{~K} / \mathrm{W}\right]\right.}\end{array}$ & $\begin{array}{c}\mathrm{r} \\
{[-]}\end{array}$ \\
\hline \multirow{3}{*}{100} & 38 & 0,414 & 0,233 & 0,214 & 4,675 \\
\hline & 50 & 0,507 & 0,282 & 0,220 & 4,545 \\
\hline & 80 & 0,707 & 0,387 & 0,233 & 4,292 \\
\hline \multirow{3}{*}{120} & 38 & 0,416 & 0,246 & 0,200 & 5,004 \\
\hline & 50 & 0,509 & 0,300 & 0,207 & 4,841 \\
\hline & 80 & 0,717 & 0,412 & 0,220 & 4,538 \\
\hline \multirow{3}{*}{140} & 38 & 0,411 & 0,254 & 0,188 & 5,332 \\
\hline & 50 & 0,505 & 0,310 & 0,195 & 5,141 \\
\hline & 80 & 0,715 & 0,431 & 0,209 & 4,775 \\
\hline \multirow{3}{*}{160} & 38 & 0,402 & 0,258 & 0,177 & 5,657 \\
\hline & 50 & 0,496 & 0,315 & 0,184 & 5,439 \\
\hline & 80 & 0,706 & 0,440 & 0,199 & 5,019 \\
\hline
\end{tabular}

* Value of $\mathrm{R}=\mathrm{R}_{\text {câmp }}$ is given in tables $1,2,3$.

\subsection{Graphical results}
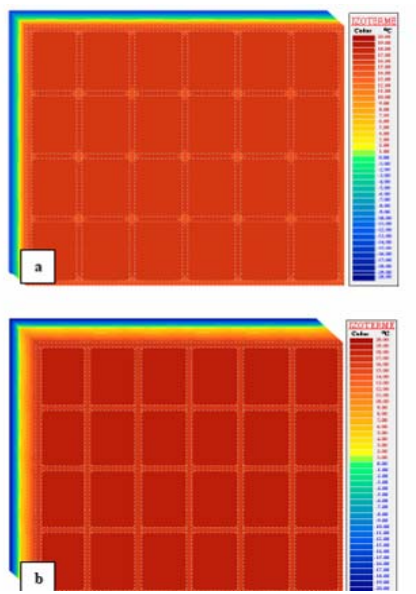

Figure 5. Isothermal surfaces for wall panel (a) uninsulated wall, (b) thermally insulated wall with 10 $\mathrm{cm}$ of EPS 


\section{RESULTS ANALYSIS}

The results obtained for $\Psi$ and $f_{\text {Rsi }}$ are very useful in the design stage when the thermal performance of the building envelope must be established (Evola, 2011; Berggren, 2013). Our research staff is on the point of publishing a thermal bridges catalogue for thermal bridges met in current practice at wood frame constructions.

Analyzing the obtained results from point 5.2 the negative influence of the thermal bridges area can be noticed. The thermal performance of the wall panel (i.e. the thermal resistance in the current field $R_{\text {câmp }}$ and the medium adjusted thermal resistance $\mathrm{R}^{\prime}$ ) increases with increasing thickness of the internal mineral wool layer $d_{v}$. For each thickness of mineral wool the R' decreases with increasing thickness of the stud $d_{m}$.

Thermal bridges effect given by the $\mathrm{r}$ ratio indicates that the thermal performance for same mineral wool thickness decreases with increasing thickness of the stud $\mathrm{d}_{\mathrm{m}}$. R' decreases compared to $\mathrm{R}_{\text {câmp with }}$ increasing thickness of the panel. The negative effect is reduced when the exterior thermal insulation layer placed on the exterior surface of the wall, increases.

The stud and OSB sheathing thicknesses are established based on mechanical resistance conditions. After establishing the dimensions based on structural conditions, is chosen the best variant from the thermal point of view in accordance to the minimum required thermal resistance for exterior walls mentioned in C107 modified in 2010 (2513 Order, 1010).

In order to obtain the best energy performance of the building, the constructive solutions having the highest adjusted thermal resistance R' must be chosen.

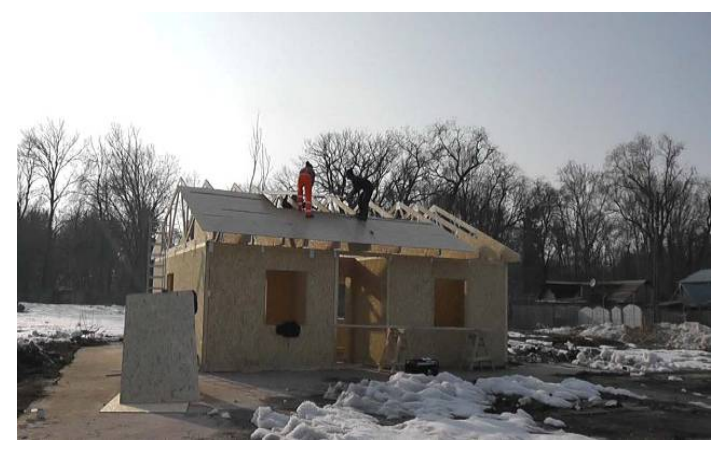

Figure 6. Execution phase of a wood structure building (www.casepanourilemn.ro)

\section{CONCLUSIONS}

If for the case of traditional structures thermal bridges are usually represented by the structural elements of reinforced concrete, for wood structure buildings the wood studs represent a thermal bridge for the thermal protection layer, because its thermal conductivity is 4 to 6 times higher than the one of the thermal insulating layer. The computing program "PSIPLAN" accurately reflects the complex heat transfer phenomena that occur through thermal bridges in buildings with wood structure.

The research was imposed due to lack of information on thermal bridges at wood structure buildings. Lately, the number of these types of buildings is increasing although that a considerable lack of research still exist on optimizing these types of structures.

The working method and the computer program are useful in correct energy design of new buildings with wood structure. The program can also be used in the rehabilitation process of existing wooden buildings in order to ensure optimal thermal efficiency. A good knowledge of the building envelope behavior will help in establishing the accurate dimensions of building services and thus reducing the $\mathrm{CO}_{2}$ emissions from building exploitation and the negative impact on the exterior environment.

\section{ACKNOWLEDGEMENTS}

Funded by the European Social Fund Program POSDRU, DMI 1.5, ID 137516-PARTING.

\section{REFERENCE}

Moga, L., Moga I., 2009. The energetic performance of the building envelope elements- intersection of linear thermal bridges. The Fifth International Workshop on Energy and Environment of Residential Buildings and The Third International Conference on Built Environment and Public Health EERB-BEPH, Guilin, Guangzhou, China.

Ascione, F., Bianco, N., De Masi, R. F., de' Rossi, F. \& Vanoli, G. P., 2013. Simplified state space representation for evaluating thermal bridges in building: Modelling, application and validation of a methodology. Appl. Therm. Eng., 61, pp. 344-354.

Cappelletti, F., Gasparella, A., Romagnoni, P. \& Baggio, P., 2011. Analysis of the influence of installation thermal bridges on windows performance: The case of clay block walls. Energy Build,. 43, pp.1435-1442.

Asdrubali, F., Baldinelli, G. \& Bianchi, F., 2012, A quantitative methodology to evaluate thermal bridges in buildings. Appl. Energy, 97, pp. 365-373. 
EN ISO 10211-1:1995, Thermal bridges in building construction- Heat flows and surface temperatures- Part 1: General calculation methods.

EN ISO 10211:2007, Thermal bridges in building construction -- Heat flows and surface temperatures -Detailed calculations.

EN ISO 10211-2:2001, Thermal bridges in building construction. Calculation of heat flows and surface temperatures. Part 2: Linear thermal bridges.

CSTB catalogue: Determination et calcul des ponts thermiques lineiques et integres des constructions en bois, Societe CTBA.

C107:2010 (2005). Normativ privind calcul termotehnic al elementelor de constructive ale cladirilor (Romanian norm for the termotechnical calculation of the construction components of buildings).

2513 Order from 22.11.2010. Modificarea Reglementării tehnice „Normativ privind calculul termotehnic al elementelor de construcție ale clădirilor", indicativ C 107:2005 (Modification of the technical regulation „Norm for the termotechnical calculation of the construction components of buildings indicative C107:2005).

Evola, G., Margani, G. \& Marletta, L., 2011. Energy and cost evaluation of thermal bridge correction in Mediterranean climate. Energy Build., 43, pp. 2385-2393.

Berggren, B. \& Wall, M., 2013. Calculation of thermal bridges in (Nordic) building envelopes - Risk of performance failure due to inconsistent use of methodology. Energy Build., 65, pp. 331-339.

Theodosiou, T. G. \& Papadopoulos, A. M., 2008. The impact of thermal bridges on the energy demand of buildings with double brick wall constructions. Energy Build., 40, pp. 2083-2089.

Tadeu, A., Simões, I., Simões, N. \& Prata, J., 2011. Simulation of dynamic linear thermal bridges using a boundary element method model in the frequency domain. Energy Build., 43, pp. 3685-3695.

Available at http://www.casepanourilemn.ro/

Gao, Y., Roux, J. J., Zhao, L. H. \& Jiang, Y., 2008. Dynamical building simulation: A low order model for thermal bridges losses. Energy Build., 40, pp. 2236-2243.

European Parliament and Council of 19 May 2010, 2010, Directive 2010/31/EU on the energy performance of buildings (recast). 
